\section{Commentary: How does the vein look? Intraoperative storage strategy and vein graft disease prevention}

\author{
Malak Elbatarny, MD, ${ }^{\mathrm{a}}$ Derrick Y. Tam, MD, ${ }^{\mathrm{b}}$ and \\ Stephen E. Fremes, MD, MSc, FRCSC ${ }^{b}$
}

Vein graft disease (VGD) post-coronary artery bypass grafting $(\mathrm{CABG})$ is a common and challenging clinical problem. Percutaneous coronary intervention of VGD is associated with significantly greater 2-year ischemic events compared with all-comers, ${ }^{1}$ and with the majority of patients with VGD having patent internal mammary grafts, repeat sternotomy is also a high-risk operation. Saphenous vein grafts (SVGs) remain the most commonly used grafts in CABG and therefore there has been increasing interest in developing techniques for improving their long-term patency. The current methods for vein graft storage, in decreasing popularity, include: various buffered saline solutions, unbuffered saline, and autologous blood, most commonly cold with heparin. ${ }^{2}$ A secondary study of vein graft preservation solution in the PREVENT IV RCT suggest that the use of buffered saline may be associated with less vein graft failure compared with saline and blood solution, highlighting the importance and need to better understand the role of vein graft preservation after harvesting.

We congratulate Perrault and colleagues ${ }^{3}$ for their elegant study in this issue of the Journal investigating the impact of intraoperative storage solution on VGD progression. The authors studied 125 individuals from 7 centers in 3 countries. All patients underwent CABG using 2 SVGs to both the circumflex and right coronary artery territory.

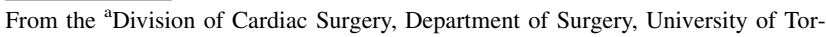
onto; and ${ }^{\mathrm{b}}$ Division of Cardiac Surgery, Department of Surgery, Schulich Heart Centre, Sunnybrook Health Sciences Centre, University of Toronto, Toronto, Ontario, Canada.

Dr Tam is supported by a CIHR Fellowship (Canada). Dr Fremes is supported by the Bernard S. Goldman Chair in Cardiovascular Surgery (Toronto, Ontario, Canada). Dr Elbatarny has nothing to disclose with regard to commercial support.

Received for publication Oct 24, 2019; revisions received Oct 24, 2019; accepted for publication Oct 24, 2019; available ahead of print Nov 20, 2019.

Address for reprints: Stephen E. Fremes, MD, MSc, FRCSC, Sunnybrook Health Sciences Centre, 2075 Bayview Ave, Room H4 05, Toronto, Ontario M4N 3M5, Canada (E-mail: stephen.fremes@sunnybrook.ca).

J Thorac Cardiovasc Surg 2021;161:107-8

$0022-5223 / \$ 36.00$

Copyright (C) 2019 by The American Association for Thoracic Surgery

https://doi.org/10.1016/j.jtcvs.2019.10.162
}

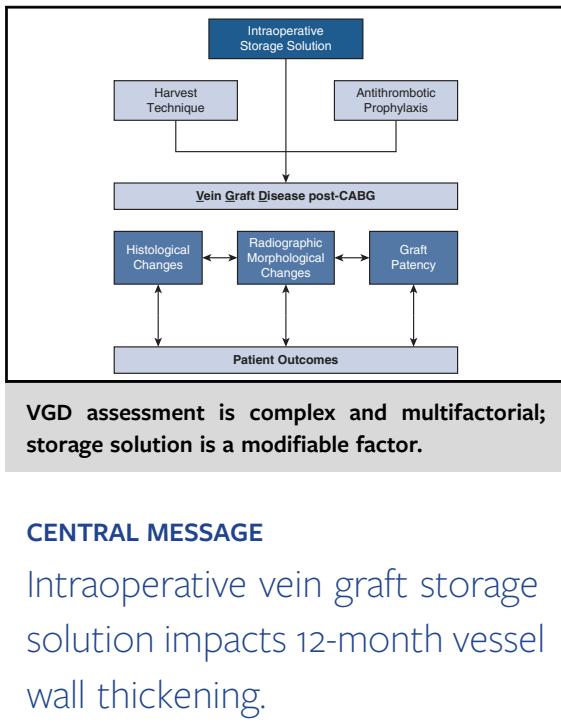

Using a within-patient, double-blinded randomization design, each of the patients' 2 vein segments were randomly assigned to normal saline or DuraGraft storage solution (Somahlution, Inc, Jupiter, Fla). The study solution, previously known as glutathione, ascorbic acid, and L-arginine (GALA), is a specialized buffered saline containing the aforementioned components. On-pump CABG was performed in $98 \%$ of cases. Duration of storage, target vessel size, and grafting areas were all equivalent between both groups. The within-patient design eliminated patient or vein-harvester confounders. Vessel diameter and graft length were equivalent between groups. Investigators used sequential multidetector computed tomography imaging to demonstrate at 12 months significantly smaller overall mean SVG wall thickness after treatment with DuraGraft compared with saline $(0.12 \pm 0.06$ vs $0.20 \pm 0.31 \mathrm{~mm}$; $P=.02)$. The effect was more pronounced in the proximal graft segments $(0.11 \pm 0.03$ vs $0.21 \pm 0.33 \mathrm{~mm} ; P=.01)$. Maximum graft narrowing was also reduced in the DuraGraft SVGs at 12 months $(4.7 \pm 12.7 \%$ vs $0.2 \pm 3.8 \%$; $P=.01$ ). We also congratulate the authors for achieving a very high SVG patency rate; the number of occlusions was 18 and similar between groups. There were no deaths or need for repeat revascularization.

This study should be interpreted in the context of some limitations. First, the primary study outcomes (change in wall thickness at 3 months and change in maximum narrowing at 12 months) were not statistically different; therefore, all other findings are exploratory. Because of multiple study endpoints, there is also an increased risk of a type 1 error. A potential unmeasured confounder could result from 
variation in the duration or volume of antegrade cardioplegia delivered through grafts; this common practice has been linked with endothelial vein damage. ${ }^{4}$ Wall thickness is a convenient and quantifiable outcome of interest; however, it remains a surrogate for vein graft atherosclerosis or occlusion. Although multidetector computed tomography wall thickness has been correlated with intravascular ultrasound (IVUS) findings in native coronary arteries, ${ }^{5}$ it has not been formally validated for clinically relevant SVG changes.

The use of optical coherence tomography, which has 10 times the resolution of IVUS, may be superior to IVUS for the detection of vascular pathology ${ }^{6}$ and has even been used to detect conduit damage intraoperatively postharvest. ${ }^{7}$ In vitro studies have shown significantly greater vein viability with DuraGraft compared with Hank's Balanced Salt Solution, with prolonged durations of storage, although longer than is typical during CABG. Early histologic changes are presumably precursors of more pronounced morphologic findings of VGD. The ability to correlate histologic and functional parameters at the time of harvest with delayed morphologic changes and clinical adverse outcomes would be highly useful and represents a potential future research direction. This may also elucidate the mechanism of action of DuraGraft on preserving SVG viability, which was outside the scope of this study. Finally, delaying progression of VGD as demonstrated by highresolution imaging may not translate to improved clinical outcomes.

Given that nearly one half of vein grafts are occluded by 10 years, ${ }^{8}$ there remains considerable room for improvement. Antithrombotic pharmacologic prophylaxis optimization may represent another strategy to optimize long-term patency. A recent network meta-analysis suggested dual antiplatelet therapy rather than aspirin monotherapy was associated with reduced VGF without increase in major bleeding risk. ${ }^{9}$ External vein graft stenting has been shown to slow progression of late VGD with high-resolution imaging, but this finding did not translate to reduced late graft failure and clinical outcomes were not assessed ${ }^{10,11}$; clinical benefit may be elucidated by the ongoing larger VEST pivotal trial (NCT03209609), which incorporates major adverse cardiac and cerebrovascular events as a secondary outcome. Finally, harvest technique may be among the most important factors. The no-touch harvest technique is associated with preserved histologic and endothelial function ${ }^{8}$ and excellent patency, perhaps even approaching that of arterial grafts in the long term. ${ }^{10-12}$

In summary, reasons for VGD are multifactorial. Potential for improvement in SVG occlusion rates into the single digits, as demonstrated in this trial, at 1 year seems feasible. Intraoperative storage solution represents a relatively simple intervention with both in vitro and clinical evidence for improvement in graft quality. Further study is required to determine the incremental benefit of ideal solution choice, among other intraoperative and perioperative variables, and to correlate these with biological changes and clinically relevant outcomes.

\section{References}

1. Redfors B, Généreux P, Witzenbichler B, McAndrew T, Diamond J, Huang X, et al. Percutaneous coronary intervention of saphenous vein graft. Circ Cardiovasc Interv. 2017;10:e004953.

2. Williams JB, Harskamp RE, Bose S, Lawson JH, Alexander JH, Smith PK, et al. The preservation and handling of vein grafts in current surgical practice: findings of a survey among cardiovascular surgeons of top-ranked US hospitals. JAMA Surg. 2015;150:681-3.

3. Perrault LP, Carrier M, Voisine P, Olson PS, Noiseux N, Jeanmart H, et al. Sequential multidetector computed tomography assessments after venous graft treatment solution in coronary artery bypass grafting. J Thorac Cardiovasc Surg. 2021;161:96-106.e2

4. Koukis I, Siminelakis S, Argiriou M, Theakos N, Takou A, Pounis G, et al. Antegrade cardioplegia as a possible cause of acute saphenous vein endothelial damage in patients undergoing on pump coronary artery bypass surgery. J Thorac Dis. 2018; 10:4302-10

5. Matsunaga E, Takaya N, Yokoyama T, Akimoto Y, Miyauchi K, Daida H. Relationship between coronary artery wall thickness measured by 64-slice multidetector computed tomography and cardiovascular risk factors. Circ J. 2009;73: 681-5.

6. Adlam D, Antoniades C, Lee R. OCT characteristics of saphenous vein graft. Atherosclerosis. 2017;4:807-9.

7. Brown EN, Burris NS, Gu J, Kon ZN, Laird P, Kallam S, et al. Thinking inside the graft: applications of optical coherence tomography in coronary artery bypass grafting. J Biomed Opt. 2007;12:051704.

8. Loesch A, Dashwood MR, Souza DSR. Does the method of harvesting the saphenous vein for coronary artery bypass surgery affect venous smooth muscle cells? iNOS immunolabelling and ultrastructural findings. Int J Surg. 2006;4: 20-9.

9. Solo K, Lavi S, Kabali C, Levine GN, Kulik A, John-Baptiste AA, et al. Antithrombotic treatment after coronary artery bypass graft surgery: systematic review and network meta-analysis. BMJ. 2019;367:15476.

10. Souza DSR, Johansson B, Bojö L, Karlsson R, Geijer H, Filbey D, et al. Harvesting the saphenous vein with surrounding tissue for CABG provides long-term graft patency comparable to the left internal thoracic artery: results of a randomized longitudinal trial. J Thorac Cardiovasc Surg. 2006;132(2).

11. Dreifaldt M, Mannion J, Hakan G, Mats L, Bodin L, Souza D. The no touch saphenous vein is an excellent alternative conduit to the radial artery eight years after CABG: a randomized trial. J Thorac Cardiovasc Surg. October 26, 2019 [Epub ahead of print].

12. Deb S, Fremes SE. Commentary: the race for the second best-the no-touch saphenous vein versus the radial artery. J Thorac Cardiovasc Surg. October 9, 2019 [Epub ahead of print]. 